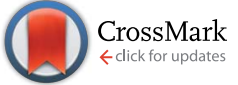

Cite this: Chem. Sci., 2016, 7, 1033

\title{
Carborane-based design of a potent vitamin D receptor agonist $\dagger$ t
}

\author{
Rocio Otero, $\S^{a}$ Samuel Seoane, $\S^{\mathrm{b}}$ Rita Sigüeiro, ${ }^{\text {ac }}$ Anna Y. Belorusova, ${ }^{c}$ \\ Miguel A. Maestro, ${ }^{d}$ Roman Pérez-Fernández, ${ }^{b}$ Natacha Rochel ${ }^{\star c}$ \\ and Antonio Mouriño*a
}

The vitamin D nuclear receptor (VDR) is a potential target for cancer therapy. It is expressed in many tumors and its ligand shows anticancer actions. To combine these properties with the application of boron neutron capture therapy (BNCT), we design and synthesize a potent VDR agonist based on the skeleton of the hormone 1 $\alpha, 25$-dihydroxyvitamin $\mathrm{D}_{3}(1,25 \mathrm{D})$ and an o-carborane (dicarba-o-closo-1,2-dodecaborane) at the end of its side chain. The present ligand is the first secosteroidal analog with the carborane unit that efficiently binds to VDR and functions as an agonist with 1,25D-like potency in transcriptional assay on vitamin $\mathrm{D}$ target genes. Moreover it exhibits similar antiproliferative and pro-differentiating activities but is significantly less hypercalcemic than 1,25D. The crystal structure of its complex with VDR ligand binding domain reveals its binding mechanism involving boron-mediated dihydrogen bonds that mimic vitamin D hydroxyl interactions. In addition to the therapeutic interest, this study establishes the basis for the design of new unconventional vitamin D analogs containing carborane moieties for specific molecular recognition, and drug research and development.

Received 19th August 2015
Accepted 26th October 2015

DOI: $10.1039 / \mathrm{c} 5 \mathrm{sc} 03084 f$

www.rsc.org/chemicalscience destroy tumors without affecting healthy tissue. ${ }^{5-8}$ The development of this technique depends on the availability of boron compounds which bind receptors in the tumors. To target tumors more specifically, derivatives of natural ligands that target receptors but also bear boron atoms have been synthesized. ${ }^{4,9,10}$ More recently, boron compounds have been shown to have broader applications in medicinal chemistry as active biomolecules such as carborane compounds that have anticancer activity or act as HIV replication inhibitors.,

Among the receptors expressed in tumors that can be targeted by carborane ligands for cancer therapy, the vitamin D receptor (VDR), a member of the nuclear receptor superfamily, is a potential candidate. ${ }^{11}$ Vitamin $\mathrm{D}_{3}$, before eliciting its physiological functions, undergoes two hydroxylations, first in the liver and then in the kidney, to produce its active form, 1 $\alpha, 25$-dihydroxyvitamin $\mathrm{D}_{3}(1,25 \mathrm{D}$, Fig. 1$)$. The hormone $1,25 \mathrm{D}$ through binding to VDR regulates a number of physiological

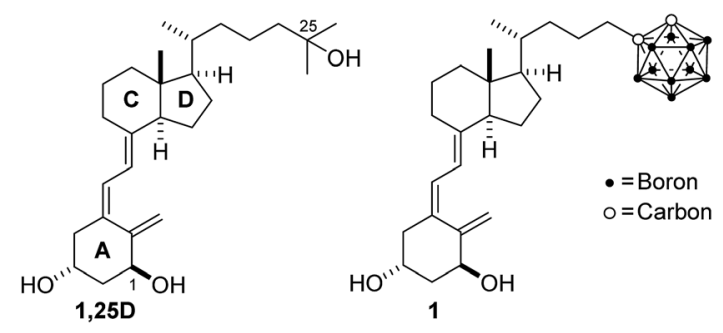

Fig. 1 Vitamin D hormone (1,25D) and the target carborane 1.
${ }^{a}$ Departamento de Química Orgánica, Laboratorio de Investigación Ignacio Ribas, Universidad de Santiago de Compostela, Avda. Ciencias s/n, 15782 Santiago de Compostela, Spain.E-mail: antonio.mourino@usc.es

${ }^{b}$ Departamento de Fisiología-CIMUS, Universidad de Santiago, Avda. Barcelona $s / n$, 15706 Santiago de Compostela, Spain

'Department of Integrative Structural Biology, IGBMC - CNRS UMR7104 - Inserm U964, 1, rue Laurent Fries, 67400 Illkirch, France.E-mail: rochel@igbmc.fr

${ }^{d}$ Departmento de Química Fundamental, Universidad de A Coruña, Campus da Zapateira s/n, 15071 A Coruña, Spain

$\dagger$ Accession number. The coordinates and structure factors are deposited in the Protein Data Bank under the accession code 5E7V.

\$ Electronic supplementary information (ESI) available: Experimental procedures, computational details, spectroscopic data and copies of ${ }^{1} \mathrm{H}$ and ${ }^{13} \mathrm{C}$ NMR spectra and characterization data for all new compounds. See DOI: 10.1039/c5sc03084f $\S$ R. Otero and S. Seoane contributed equally. 
and pathological processes, including cell proliferation and differentiation, which has led to the study of its effects in cancer. Significant antitumor activity (i.e. anti-proliferative effects, induction of apoptosis, stimulation of differentiation, and inhibition of invasion and metastasis) has been demonstrated for 1,25D in different types of cancers including breast, prostate, colon, and acute myeloid leukemia. ${ }^{12,13}$ In fact, recent studies have established that VDR expression should be taken into account for breast cancer treatment. ${ }^{\mathbf{1 4}}$

\section{Results and discussion}

In this study, we describe the design, the synthesis and the functional and structural characterization of a novel vitamin D analog bearing an $o$-carborane group at the side chain (1, Scheme 1). To date, only a few simple carborane mimics of vitamin $\mathrm{D}$ have been developed. These compounds, which show reduced activity, lack the $1,25 \mathrm{D}$ A-ring moiety and possess a $p$-carborane unit that replaces the natural CD-rings. ${ }^{15-18}$ The $p$-carborane unit of theses vitamin D mimics interacts with the VDR only through van der Waals interactions. ${ }^{15}$ More recently ${ }^{19}$ the same authors synthesized structure-related compounds which exhibit similar pro-differentiation activities in HL-60 cells as the natural 1,25D hormone.

Carborane $\mathbf{1}$ is the first secosteroidal vitamin D analog with the carborane unit that efficiently binds to the VDR ligand binding domain (LBD) and is as transcriptionally active as $1,25 \mathrm{D}$ on vitamin $\mathrm{D}$ target genes, but is significantly less hypercalcemic than $1,25 \mathrm{D}$. In addition to the therapeutic interest, our study helps clarify the functional behavior of this molecule.

\section{Design}

On the basis of the crystal structure of an engineered active ligand-binding domain of the human vitamin D receptor (hVDR LBD) bound to $1,25 \mathrm{D},{ }^{20}$ which reveals an additional hydrophobic space around the side chain, and inspired by the biological
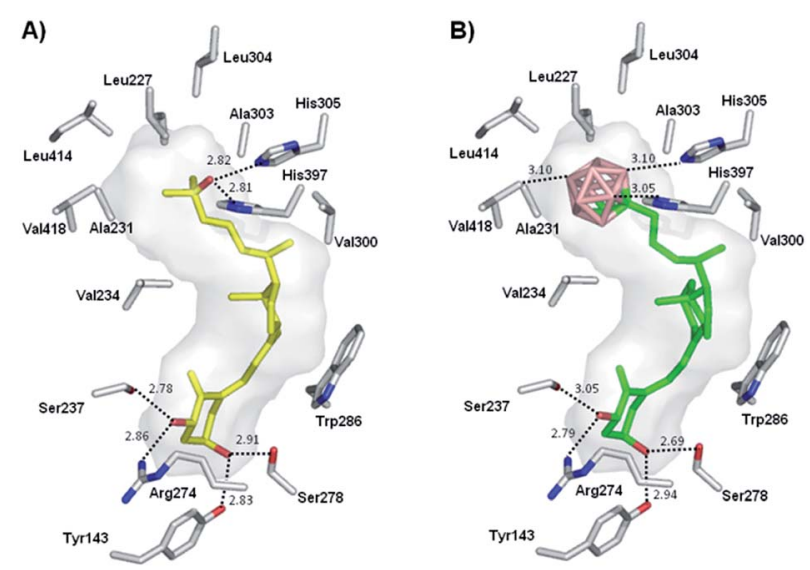

Fig. 2 (A) Structure of 1,25D (yellow) in complex with hVDR LBD (PDB ID: 1DB1). (B) Docked structure of analog 1 (green) into hVDR LBD. Distances are shown in $\AA$ profile of carboranes, ${ }^{3,4}$ we designed a new analog bearing an $o$-carborane moiety at the end of the side chain (1, Fig. 1). Docking results show that the novel vitamin $\mathrm{D}$ analog fits reasonably well in the ligand binding pocket. The ligand adopts the canonical active conformation in which the rings and the triene system of the new ligand have similar positions as the natural hormone $1,25 \mathrm{D}$. The A-ring hydroxyl groups form hydrogen bonds with the same amino acid residues as 1,25D. Remarkably, the side-chain carborane moiety binds by unusual dihydrogen bonding with the His305 and His397 residues (Fig. 2).

\section{Synthesis}

Our plan for the synthesis of the target analog $\mathbf{1}$ entailed formation of the $o$-carborane unit late in the synthesis to circumvent anticipated problems related to carborane chemistry and characterization. Construction of the carborane-containing side was envisaged to arise by reaction between alkyne 2 and decaborane $\left(\mathrm{B}_{10} \mathrm{H}_{14}\right) .{ }^{4}$ It was not clear at this point if the labile vitamin $\mathrm{D}$ triene system would withstand the reaction conditions. The vitamin D triene system would arise by a Pdcatalyzed cascade process ${ }^{21}$ involving ring-closure of enol-triflate 4 and coupling with boronate 3 (Scheme 1).

The synthesis of carborane $\mathbf{1}$ is illustrated in Scheme 2 and started with known Inhoffen-Lythgoe diol (5a), ${ }^{22}$ which was converted to known tosylate $\mathbf{5 b}$. Exposure of tosylate $\mathbf{5 b}$ to magnesium reagent $6^{23}$ in the presence of catalytic $\mathrm{Li}_{2} \mathrm{CuCl}_{4}$ provided alcohol 7a (96\%), which was oxidized with pyridinium dichromate to the corresponding ketone $7 \mathbf{b}(98 \%)$. Wittig chemistry on 7b using ylide $\mathrm{Ph}_{3} \mathrm{P}=\mathrm{CHBr}$ (prepared by treatment of $\mathrm{Ph}_{3} \mathrm{PCH}_{2}$ $\mathrm{Br}_{2}$ with $\left.\mathrm{KO} t \mathrm{Bu}\right)^{\mathbf{2 1 , 2 4}}$ provided vinyl bromide 8 (77\%), which was converted to boronate $3(88 \%)$ by metalation with $t \mathrm{BuLi}$, reaction of the organolithium with triisopropyl boronate, and transesterification with pinacol. The triene system of 2 was constructed in $90 \%$ yield by Pd-catalyzed assembling ${ }^{21}$ of boronated 3 with the Pd-intermediate resulting from ring-closure of enoltriflate $4^{25}$ in the presence of $\mathrm{PdCl}_{2}\left(\mathrm{PPh}_{3}\right)_{2}$ and $\mathrm{K}_{3} \mathrm{PO}_{4}$, followed by desilylation of the side chain (HF). In the crucial step, the carborane unit of 1 was introduced in the side chain in $43 \%$ yield by reaction of alkyne 2 with decaborane in the presence of $\mathrm{N}, \mathrm{N}$ dimethylaniline. Finally, deprotection of $\mathbf{1 0}$ furnished the desired carborane analog 1 in 93\% yield (19\% overall yield, 9 steps).

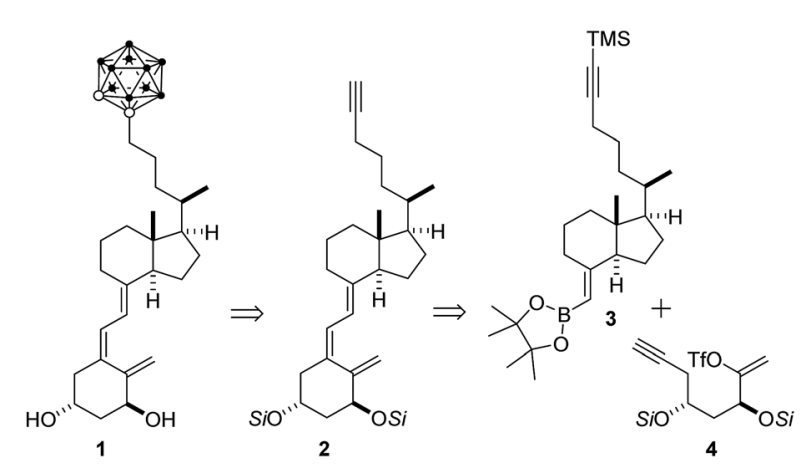

Scheme 1 Retrosynthesis of target carborane $1 . S i=$ protecting group, $\mathrm{TMS}=\mathrm{SiMe}_{3}$ 


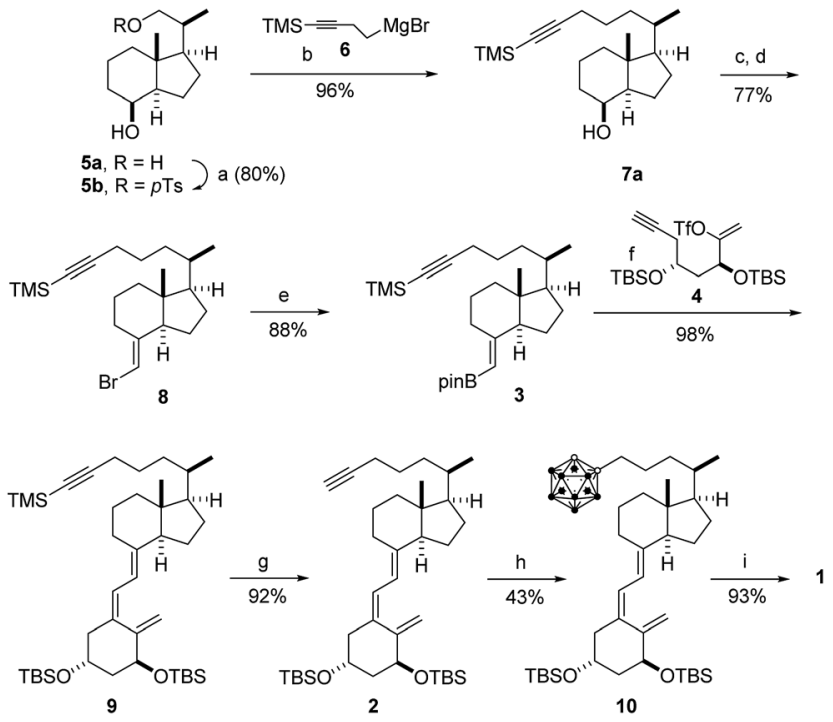

Scheme 2 Synthesis of target analog 1. Reagents and conditions: (a) $p \mathrm{TsCl}$ (1.5 equiv.), py, $0{ }^{\circ} \mathrm{C}, 12 \mathrm{~h}$; (b) 6 (4 equiv.), $\mathrm{Et}_{2} \mathrm{O} / \mathrm{THF}(1: 1)$; $\mathrm{Li}_{2} \mathrm{CuCl}_{4}$ (0.01 equiv.), THF, $-78^{\circ} \mathrm{C} \rightarrow 23^{\circ} \mathrm{C}, 12 \mathrm{~h}$; (c) oxidation of $7 \mathrm{a}$ to the corresponding ketone $7 \mathrm{~b}$ : $\mathrm{PDC}$ (3 equiv.), $\mathrm{CH}_{2} \mathrm{Cl}_{2}, 23^{\circ} \mathrm{C}, 5 \mathrm{~h}$; (d) $\left(\mathrm{Ph}_{3} \mathrm{PCH} \mathrm{H}_{2} \mathrm{Br}\right) \mathrm{Br}$ (8 equiv.), tol, ultrasound, $15 \mathrm{~min}$; KOtBu in THF (7.9 equiv., $1 \mathrm{M}),-15^{\circ} \mathrm{C} \rightarrow 0{ }^{\circ} \mathrm{C}, 2.5 \mathrm{~h}$, then $7 \mathrm{~b}$ in tol, $-15^{\circ} \mathrm{C} \rightarrow 23^{\circ} \mathrm{C}, 3 \mathrm{~h}$; (e) tol/THF (3 : 1), $-78^{\circ} \mathrm{C}$, tBuLi (2 equiv.), $1 \mathrm{~h} ; \mathrm{B}(\mathrm{O} i \mathrm{Pr})_{3}$ (1.5 equiv.), $1.5 \mathrm{~h}$; pinacol (1.3 equiv.), $-78{ }^{\circ} \mathrm{C} \rightarrow 23{ }^{\circ} \mathrm{C}, 4 \mathrm{~h}$; (f) 4 (1 equiv.), $\mathrm{K}_{3} \mathrm{PO}_{4}$ (27 equiv., aqueous sol, $2 \mathrm{M}), \mathrm{THF}, \mathrm{PdCl}_{2}\left(\mathrm{PPh}_{3}\right)_{2}(0.05$ equiv.), $2 \mathrm{~h}$; (g) $\mathrm{K}_{2} \mathrm{CO}_{3}, \mathrm{MeOH}, 23^{\circ} \mathrm{C}, 14 \mathrm{~h}$; (h) $\mathrm{PhNMe}_{2}$ (6.5 equiv.), tol, decaborane $\left(\mathrm{B}_{10} \mathrm{H}_{14}, 3\right.$ equiv.), $110{ }^{\circ} \mathrm{C}, 1 \mathrm{~h}$; (i) $\mathrm{HF}\left(48 \%, 2.5\right.$ equiv.), $\mathrm{CH}_{2} \mathrm{Cl}_{2} / \mathrm{CH}_{3} \mathrm{CN}$ (2:1), $23^{\circ} \mathrm{C}, 12 \mathrm{~h} . p \mathrm{TsCl}=p$-toluenesulfonyl chloride, $\mathrm{PDC}=$ pyridinium dichromate, $p y=$ pyridine, tol $=$ toluene, $\mathrm{TBS}=\mathrm{SitBuMe}_{2}$.

\section{Functional activity}

We next analyzed the biological properties of carborane $\mathbf{1}$ in various cell lines. The biological transcriptional activity of $\mathbf{1}$, as compared to 1,25D, was evaluated in human MCF-7 breast cancer cells. Both compounds at $10^{-8}$ and $10^{-7} \mathrm{M}$ concentrations significantly decreased cell proliferation with respect to control cells (Fig. 3a) although they are 3-fold less effective than calcipotriol. ${ }^{26}$ Carborane $\mathbf{1}$ also showed similar differentiationinducing activity compared to $1,25 \mathrm{D}$ in HaCaT keratinocytes (Fig. 3b). Competitive binding assay demonstrated that VDR binding affinity of 1 was two times higher than that of 1,25D $\left(\mathrm{IC}_{50}: 2.9 \times 10^{-9} \mathrm{M}\right.$ vs. $6.8 \times 10^{-9} \mathrm{M}$, respectively) (Fig. 3c). Ligand-induced transcriptional activities were determined in HEK 293 cells transiently transfected with expression vectors encoding the full-length hVDR and a luciferase reporter plasmid encompassing the promoter region of hCYP24A1. We found that VDR transcriptional activity is induced by lower doses of ligand 1 as compared with 1,25D, with $\mathrm{EC}_{50}$ of $1.4 \times$ $10^{-10} \mathrm{M}$ (Fig. 3d). In addition, using MCF-7 cells, we evaluated the effects of carborane 1 administration on a vitamin $\mathrm{D}$ target gene by real-time PCR. 1,25D and carborane 1 showed similar biological potency to induce CYP24A1 mRNA expression (Fig. 3e). Finally, serum calcium levels were evaluated in mice 21 days after intraperitoneal administration of 1,25D or the carborane 1. Mice treated with carborane 1 did not develop hypercalcemia and they had significantly lower calcium levels

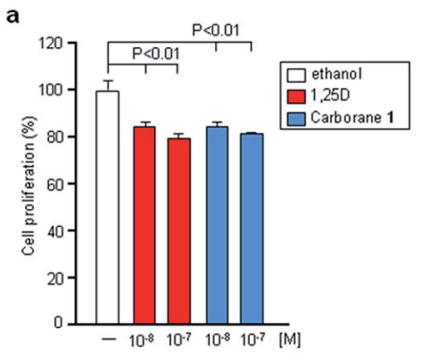

b

c

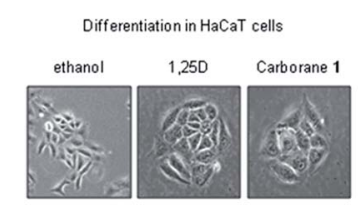

d

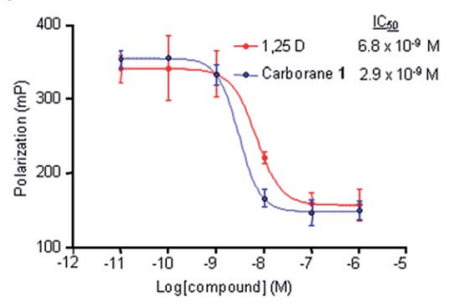

e
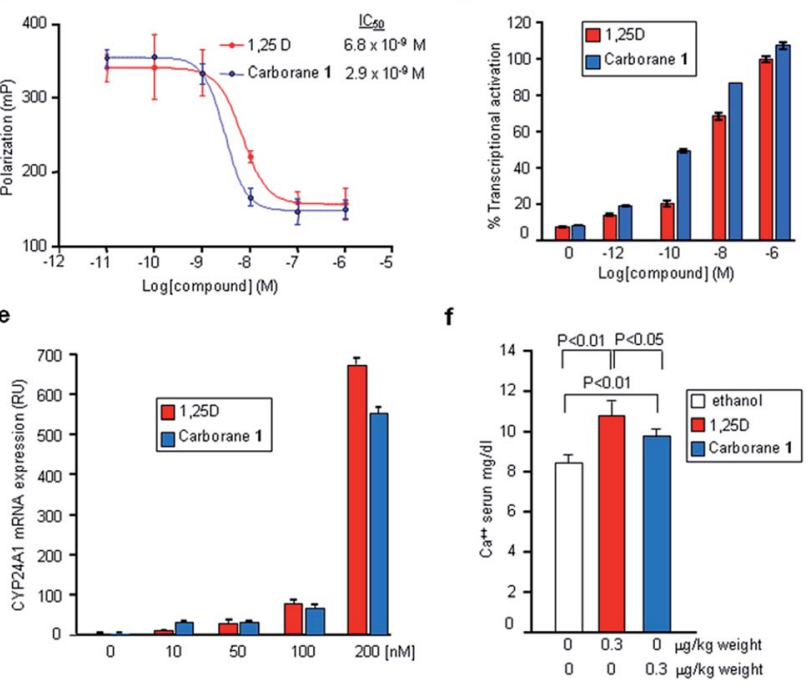

Fig. 3 Biological characterization of the carborane 1. (a) Cell proliferation in human MCF-7 breast adenocarcinoma cells. $P<0.01$ vs. control cells. (b) Differentiation activity in human $\mathrm{HaCaT}$ keratinocytes cells. (c) Vitamin D receptor binding. Competitive binding of 1,25D and carborane 1 to the full-length human VDR. IC 50 values are derived from dose-response curves. (d) Transcriptional responses of hVDR in HEK293 EBNA cells. (e) Real-time PCR of CYP24A1 mRNA levels in human MCF-7 breast cancer cells. (f) Calcium levels in sera of mice treated with 1,25D and carborane 1. Error bars represent standard deviation (SD).

than $1,25 \mathrm{D}$-injected mice $(P=0.03$, Fig. $3 f)$. Thus, carborane 1 strongly binds to VDR, induces similar biological activities and displays reduced calcemic effects.

\section{Crystal structure}

To decipher the mode of recognition of carborane 1 by the VDR, we co-crystallized the zebrafish wild-type VDR LBD in complex with the ligand and the coactivator peptide corresponding to the second LXXLL motif of SRC-2 and solved the structure with a resolution up to $2.4 \AA$ A. Although numerous carborane ligands for nuclear receptors have been synthesized $^{27-29}$ very few of them have been crystallized as proteinligand complexes. ${ }^{16}$ The data collection and refinement statistics of the structure are summarized in ESI Table $1 . \$$ The overall structure (Fig. 4a) is highly homologous to the VDR$1,25 \mathrm{D}$ structure with the insertion region between helices $\mathrm{H} 2$ and $\mathrm{H} 3$ not visible in the electron density map indicating local disorder of this region. ${ }^{30}$ Despite the bulky carborane moiety at the end of the side chain, the ligand-VDR complex adopts the canonical active conformation of the 1,25-VDR complex. 


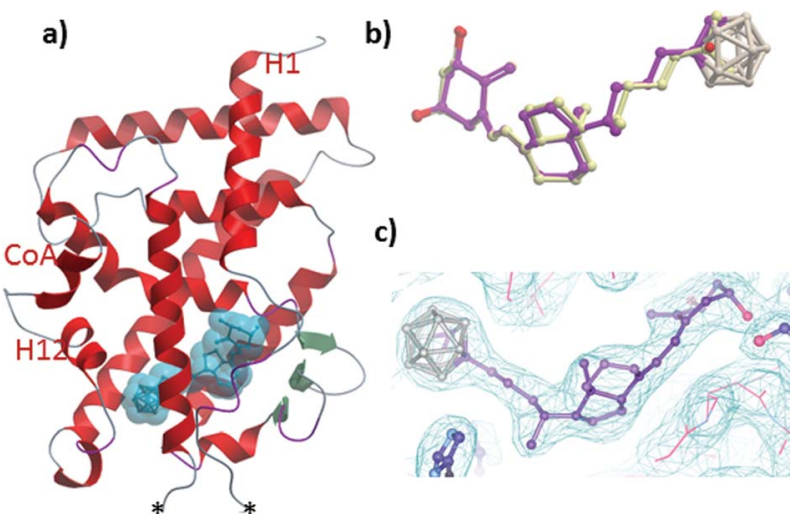

Fig. 4 (a) Overall structure of the zVDR LBD bound to the carborane 1 and the coactivator peptide. The stars indicate the insertion region not visible in the electron density map. (b) Overlay of 1,25D (carbon atoms in yellow and oxygen atoms in red) with 1 (violet) within zVDR LBD complexes. (c) The carborane 1 shown in the $2 F_{\mathrm{o}}-F_{\mathrm{c}}$ electron density map contoured at $1 \sigma$.

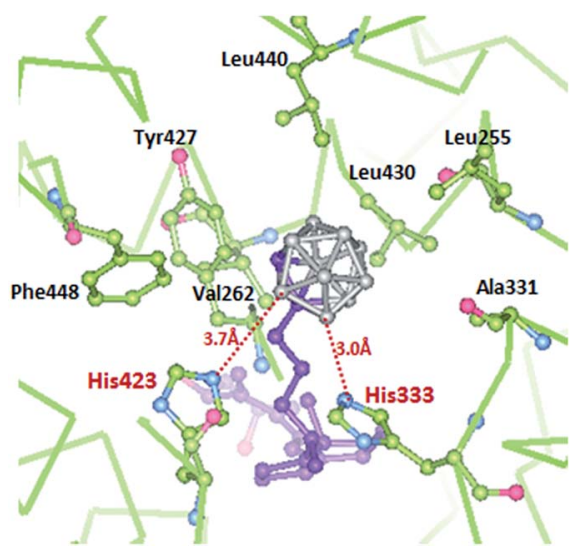

Fig. 5 Details of the interactions mediated by the carborane moiety of ligand 1 with residues of the ZVDR LBD at a $3.8 \AA$ distance cutoff. Dihydrogen bonds between boron atoms and His333 and His423 are shown by red dashed lines. Distances are shown in $\AA$.

The position and conformation of the activated helix $\mathrm{H} 12$ in the zVDR complex is strictly maintained in its agonistic position (Fig. 4a). ${ }^{30}$ When compared to the zVDR LBD-1,25D structure, the $\mathrm{C} \alpha$ atoms of the zVDR LBD-carborane complex have a root mean square deviation of $0.3 \AA$ over 238 residues. However, small shifts in secondary structural elements are observed for the loop H6-H7 and the last turn of helix H11, shifted by $0.6 \AA$. The ligand is buried in the predominantly hydrophobic pocket and adopts the same orientation as 1,25D (Fig. 4b and c). Regarding the interface VDR/coactivator peptide, we observed that contacts between protein residues and the coactivator peptide are conserved. The $\mathrm{C} 1-\mathrm{OH}$ and $\mathrm{C} 3-\mathrm{OH}$ groups of the ligand form similar $\mathrm{H}$-bonds as 1,25D.

The secosteroidal part of the ligand forms similar interactions with the zVDR ligand binding pocket compared to $1,25 \mathrm{D}$. The side-chain adopts a conformation slightly different than that observed for $1,25 \mathrm{D}$ as a consequence of the carborane moiety and the longer length of the side chain $(8.9 \AA$ instead of $6.5 \AA$ ). The carborane group forms extensive interactions with Leu255, Leu258, Ala259, Val262, Ala331, His333, His423, Tyr427, Leu430, and C-terminal residues: Leu440, Val444 and Phe448. Stronger contacts are observed with Ala259, Ala331 and Leu440 compared to 1,25D. The two histidines His333 and His423 interacts with boron atoms (Fig. 5). Although the resolution of the crystal structure (2.4 ̊̊) is not sufficient to resolve the position of the $\mathrm{H}$ atoms, on the basis of the hydride-like hydrogens at the boron atoms, we considered that in the VDR-carborane complex the two histidines interact with boron atoms through unconventional (BH $\cdots \mathrm{HN}$ ) dihydrogen bonds (Fig. 5), replacing the H-bonds formed between the $\mathrm{C} 25-\mathrm{OH}$ group of the natural ligand and both histidines.

As hydrogen atoms at $\mathrm{CH}$ of carborane are far more acidic than those at $\mathrm{BH}$, interaction between carborane $\mathrm{CH}$ and histidine would also be possible. ${ }^{31}$ Unconventional dihydrogen bonds with amino acids residues have been already reported. ${ }^{32}$ Overall, the numerous contacts among the atoms of the carborane and hydrophobic residues of $\mathrm{H} 3, \mathrm{H} 11$ and $\mathrm{H} 12$ significantly stabilize the agonist conformation of VDR in agreement with the agonist potency of this novel compound. The crystal structures of some of these $p$-carborane VD mimics revealed weaker $\mathrm{H}$-bonds compared to $1,25 \mathrm{D}$ and lack the crucial $\mathrm{CH}-\pi$ interaction with Trp. ${ }^{18}$ Remarkably, our carborane 1 that occupies the crucial anchoring points of the natural ligand to VDR, binds tighter $(2.4 \times)$ to VDR and is slightly more potent in transcriptional activation than $1,25 \mathrm{D}$.

\section{Conclusions}

An unique secosteroidal vitamin $\mathrm{D}$ analog bearing an $o$-carborane unit at the side chain has been designed, synthesized and biologically tested. In comparison with the natural hormone 1,25D, the novel analog, which lacks the 25-hydroxy group, strongly binds to VDR, induces similar biological activities and displays reduced calcemic effects. The carborane unit mimics the interaction of the 25-hydroxyl group of the natural hormone with the VDR and shows additional hydrophobic contacts between the boron atoms and important residues of helix H12. The crystal structure of the analog in complex with the zebrafish wild-type VDR-LBD, reveals that the carborane cage interacts efficiently through extensive van der Waals interactions and dihydrogen bonds with the two histidines His333 and His423. These results establish the basis for the rational design of new unconventional vitamin $\mathrm{D}$ analogs containing carborane moieties for specific molecular recognition, and drug research and development.

\section{Acknowledgements}

We thank the Spanish Ministry of Economy and Innovation (MEI, SAF2010-15291 and SAF2012-38240), Xunta de Galicia (project GPC2014/001), Agence Nationale de la Recherche (ANR13-BSV8-0024-01), French Infrastructure for Integrated Structural Biology (FRISBI) (ANR-10-INSB-05-01), and INSTRUCT as part of the European Strategy Forum on Research 
Infrastructures (ESFRI), for financial support and CESGA for computing time. R. O. thanks the Spanish MEI for an FPI fellowship (BES-2011-0419192). S. S. thanks the Asociación Española Contra el Cáncer for a fellowship (AIOA1101SEOA). R. S. thanks the Xunta de Galicia for a postdoctoral fellowship (POS-A/2012/112). We thank Oliver Smart (Global Phasing Ltd), Alastair McEwen (IGBMC) and the staff of PX1 (SOLEIL synchrotron) for their collaborations.

\section{Notes and references}

1 V. I. Bregadze, Chem. Rev., 1992, 92, 209.

2 E. Meggers, Angew. Chem., Int. Ed., 2011, 50, 2442.

3 M. Scholz and E. Hey-Hawkins, Chem. Rev., 2011, 111, 7035.

4 F. Issa, M. Kassiou and L. M. Rendina, Chem. Rev., 2011, 111, 5701.

5 M. F. Hawthorne, Angew. Chem., Int. Ed., 1993, 32, 950.

6 A. H. Soloway, W. Tjarks, B. A. Barnum, F.-G. Rong, R. F. Barth, I. M. Codogni and J. G. Wilson, Chem. Rev., 1998, 98, 1515.

7 J. F. Valliant, K. J. Guenther, A. S. King, P. Morel, P. Schaffer, O. O. Sogbein and K. A. Stephenson, Coord. Chem. Rev., 2002, 232, 173.

8 A. F. Armstrong and J. F. Valliant, Dalton Trans., 2007, 4240.

9 D. A. Feakes, R. C. Waller, D. K. Hathaway and V. S. Morton, Proc. Natl. Acad. Sci. U. S. A., 1999, 96, 6406.

10 D. Alberti, A. Toppino, S. G. Crich, C. Meraldi, C. Prandi, N. Protti, S. Bortolussi, S. Altieri, S. Aime and A. Deagostino, Org. Biomol. Chem., 2014, 12, 2457.

11 D. D. Bikle, Chem. Biol., 2014, 21, 319.

12 K. K. Deeb, D. L. Trump and C. S. Johnson, Nat. Rev. Cancer, 2007, 7, 684 .

13 D. Feldman, A. V. Krishnan, S. Swami, E. Giovannucci and B. J. Feldman, Nat. Rev. Cancer, 2014, 14, 342.

14 S. Santagata, A. Thakkar, A. Ergonul, B. Wang, T. Woo, R. Hu, J. C. Harrell, G. McNamara, M. Schwede, A. C. Culhane, D. Kindelberger, S. Rodig, A. Richardson, S. J. Schnitt, R. M. Tamimi and T. A. Ince, J. Clin. Invest., 2014, 124, 859.

15 S. Fujii, H. Masuno, Y. Taoda, A. Kano, A. Wongmayura, M. Nakabayashi, N. Ito, M. Shimizu, E. Kawachi,
T. Hirano, Y. Endo, A. Tanatani and H. Kagechika, J. Am. Chem. Soc., 2011, 133, 20933.

16 A. Wongmayura, S. Fujii, S. Ito, A. Kano, Y. Taoda, E. Kawachi, H. Kagechika and A. Tanatani, Bioorg. Med. Chem. Lett., 2012, 22, 1756.

17 S. Fujii, A. Kano, C. Songkram, H. Masuno, Y. Taoda, E. Kawachi, T. Hirano, A. Tanatani and H. Kagechika, Bioorg. Med. Chem., 2014, 22, 1227.

18 S. Yamada and M. Makishima, Trends Pharmacol. Sci., 2014, 35, 324 .

19 S. Fujii, R. Sekine, A. Kano, H. Masuno, C. Songkram, E. Kawachi, T. Hirano, A. Tanatani and H. Kagechika, Bioorg. Med. Chem., 2014, 22, 5891.

20 N. Rochel, J. M. Wurtz, A. Mitschler, B. Klaholz and D. Moras, Mol. Cell, 2000, 5, 173.

21 P. Gogoi, R. Sigüeiro, S. Eduardo and A. Mouriño, Chem.Eur. J., 2000, 16, 1432.

22 H. H. Inhoffen, G. Quinckert, S. Schuzt, G. Friedrich and E. Tober, Chem. Ber., 1958, 91, 781.

23 J. Bian, M. Van Wingerden and J. M. Ready, J. Am. Chem. Soc., 2006, 128, 7428.

24 B. M. Trost, J. Dumas and M. Villa, J. Am. Chem. Soc., 1992, 114, 9836.

25 A. Mouriño, M. Torneiro, C. Vitale, S. Fernández, J. PérezSestelo, S. Anné and C. Gregorio, Tetrahedron Lett., 1997, 38, 4713.

26 J. Wietrzyk, M. Chodynski, H. Fitak, E. Wojdat, A. Kutner and A. Opolski, Anti-Cancer Drugs, 2007, 18, 447.

27 Y. Endo, T. Yoshimi, K. Ohta, T. Suzuki and S. Ohta, J. Med. Chem., 2005, 48, 3941.

28 T. Goto, K. Ohta, S. Fuji, S. Ohta and Y. Endo, J. Med. Chem., 2010, 53, 4917.

29 T. Iijima, Y. Endo, M. Tsuji, E. Kawachi, H. Kagechika and K. Shudo, Chem. Pharm. Bull., 1999, 47, 398.

30 F. Ciesielski, N. Rochel and D. Moras, J. Steroid Biochem. Mol. Biol., 2007, 103, 235.

31 J. M. Oliva, P. von Ragué Schleyer, G. Aullón, J. I. Burgos, A. Fernández-Barbero and I. Alkorta, Phys. Chem. Chem. Phys., 2010, 12, 5101.

32 J. Fanfrlík, M. Lepsík, D. Horinek, Z. Havlas and P. Hobza, ChemPhysChem, 2006, 7, 1100. 